\title{
Thin and fat cows, and the nonlinear genetic relationship between body condition score and fertility
}

\author{
F. Tiezzi, ${ }^{*} \dagger$ C. Maltecca, $†$ A. Cecchinato, ${ }^{*}$ M. Penasa, ${ }^{* 1}$ and G. Bittante ${ }^{*}$ \\ *Department of Agronomy, Food, Natural Resources, Animals and Environment, University of Padova, Viale dell'Università 16, \\ 35020 Legnaro (PD), Italy \\ †Department of Animal Science, North Carolina State University, Raleigh 27695
}

\begin{abstract}
Thin and fat cows are often credited for low fertility, but body condition score (BCS) has been traditionally treated as a linear trait when genetic correlations with reproductive performance have been estimated. The aims of this study were to assess genetic parameters for fertility, production, and body condition traits in the Brown Swiss population reared in the Alps (BolzanoBozen Province, Italy), and to investigate the possible nonlinearity among BCS and other traits by analyzing fat and thin cows. Records of BCS measured on a 5-point scale were preadjusted for year-season and days in milk at scoring, and were considered positive (1) for fat cows if they exceeded the value of 1 residual standard deviation or null (0) otherwise, whereas positive values for thin cows were imputed to records below -1 residual standard deviation. Fertility indicators measured on first- and second-parity cows were interval from parturition to first service, interval from first service to conception, interval from parturition to conception, number of inseminations to conception, conception at first service, and nonreturn rate at $56 \mathrm{~d}$ after first service. Production traits were peak milk yield, lactation milk yield, and lactation length. Data were from 1,413 herds and included 16,324 records of BCS, fertility, and production for first-parity, and 10,086 fertility records for second-parity cows. Animals calved from 2002 to 2007 and were progeny of 420 artificial insemination bulls. Genetic parameters for the aforementioned traits were obtained under univariate and bivariate threshold and censored linear sire models implemented in a Bayesian framework. Posterior means of heritabilities for BCS, fat cows, and thin cows were 0.141, 0.122, and 0.115 , respectively. Genetic correlations of body condition traits with contemporary production were moderate to high and were between -0.556 and 0.623 .
\end{abstract}

Received March 28, 2013.

Accepted June 18, 2013.

${ }^{1}$ Corresponding author: mauro.penasa@unipd.it
Body condition score was moderately related to fertility in first $(-0.280$ to 0.497$)$ and second $(-0.392$ to $0.248)$ lactation. The fat cow trait was scarcely related to fertility, particularly in first-parity cows $(-0.203$ to 0.281). Finally, the genetic relationships between thin cows and fertility were higher than those between BCS and fertility, both in first $(-0.456$ to 0.431$)$ and second $(-0.335$ to 0.524$)$ lactation. Body condition score can be considered a predictor of fertility, and it could be included in evaluation either as linear measure or as thin cow. In the second case, the genetic relationship with fertility was stronger, exacerbating the poorest body condition and considering the possible nonlinearity between fertility and energy reserves of the cow.

Key words: body condition score, fertility, thin and fat cow, genetic parameter

\section{INTRODUCTION}

Genetic evaluation for female fertility in dairy cattle relies on direct measures of reproduction parameters (Gredler et al., 2007; Miglior, 2007; Nilforooshan et al., 2010), or correlated traits, such as angularity (Biffani et al., 2005), MUN (Mitchell et al., 2005), and BCS (Pryce et al., 2001; Berry et al., 2003; Dal Zotto et al., 2007). Body condition score is considered a management tool to evaluate both energy status and body fat reserves of a live animal through visual and tactile appraisal (Murray, 1919; Edmonson et al., 1989). Several scoring systems have been proposed to record BCS: 0 to 5 (Lowman et al., 1973), 1 to 5 (Wildman et al., 1982; Edmonson et al., 1989), 1 to 6 (Mulvaney, 1977), 1 to 8 (Earle, 1976), and 1 to 10 (Roche et al., 2004) point scales. The general rationale is that low values reflect emaciation and high values equate to obesity (Roche et al., 2009).

Body condition score in dairy cattle is usually performed by trained technicians, whose accuracy and repeatability have been widely studied (Ferguson et al., 1994; Hady et al., 1994; Veerkamp et al., 2002). When measurements of BCS are compared intra- and interclassifier, results can be discordant. Edmonson 
et al. (1989) found good consistency in scoring, as interclassifier variability was small, and accumulated experience did not show any significant effect on the classifier's repeatability. Veerkamp et al. (2002) found that genetic correlations between scorings of different classifiers treated as different traits were seldom significantly different from unity, whereas Kristensen et al. (2006) found that training was a major factor in defining repeatability within and across technicians.

In high-producing dairy cattle, constrained feed intake jointly with high milk yield lead to mobilization of adipose tissue reserves in response to the energy deficit, which denotes the pattern of loss (from beginning to mid lactation) and recovery (in late lactation), such that the change in BCS can be considered a predictor of energy balance. Because of the subjective measure of BCS and the discrete nature of the scale, the results of 2 subsequent scorings of an animal can be biased; therefore, especially for genetic purposes, the BCS score as such and not its change over time, has been found to be a reliable predictor of energy balance (Coffey et al., 2003; Roche et al., 2009; Banos and Coffey, 2010). Moreover, Waltner et al. (1993), Gallo et al. (1996), and Pryce et al. (2001) found this pattern to be different across lactations and productive level, as primiparous cows tended to lose less condition than second- and later-parity animals.

From a genetic point of view, Veerkamp et al. (2001), Pryce et al. (2002), and Dal Zotto et al. (2007) reported unfavorable correlations between BCS and milk yield $(-0.30$ to -0.48$)$, indicating that cows genetically predisposed to produce high amounts of milk are also predisposed to be less conditioned. Phenotypic correlations were also negative but weaker, probably due to environmental effects mitigating the loss of condition in high-producing cows.

The loss of body condition has been shown to be phenotypically related to fertility problems (Domecq et al., 1997; Suriyasathaporn et al., 1998; Gillund et al., 2001). Cows showing bad conditioning did not necessarily have bad fertility, but the loss of BCS in early lactation involved low reproductive performance (Bastin and Gengler, 2013). A veterinary approach to fertility problems considers negatively both extremes of cow's condition, namely the "thin cow" and the "fat cow" syndromes (Studer, 1998), and the relationships between nutrition, body reserves, milk yield, and fertility in both thin and fat cows have been extensively reviewed (Heuer et al., 1999; Friggens et al., 2010; Remppis et al., 2011). The negative energy balance (NEB) after calving impairs fertility both at cow and oocyte level. Not only does NEB delay the beginning of cyclic sexual activity and lowers the external signs of estrus, but causes also an impaired uterine environment that is likely to be a major contributor to the higher incidence of early embryonic death found in repeat breeders (Hill and Gilbert, 2008; Wathes et al., 2012). Oocytes maturated during severe NEB often show compromised quality (Leroy et al., 2008). In addition, both positive and NEB increase the circulating lipids at the ovary level, which causes severe damage to the survivability of oocytes, also because of impaired mitochondrial function and vulnerability to oxidative stress (Wrenzycki et al., 2000; Rizos et al., 2003; Van Hoeck et al., 2011). From a genetic point of view, BCS treated as a linear trait has been found to be positively related to good fertility. Using a single scoring per cow during lactation, Pryce et al. (2002), Dechow et al. (2004), Dal Zotto et al. (2007), Rossoni et al. (2007a), and Zink et al. (2011) reported genetic correlations of BCS with calving interval or days open ranging from -0.30 to -0.67 , which means that genetically less conditioned cows are likely to take a longer time to conceive after calving. Several authors analyzed repeated observations of BCS within a given lactation, modeling this trait using multipletrait (Dechow et al., 2001; Gallo et al., 2001; Berry et al., 2003) and random regression (Veerkamp et al., 2001; De Haas et al., 2007b; Bastin et al., 2010a) models. On average, genetic correlations were concordant with those reported for studies on single measures of $\mathrm{BCS}$, although the use of repeated measures allowed the identification of stronger relationships in early and mid lactation.

Body condition score can be referred to as a predictor of fertility in dairy cattle populations where direct assessment of reproductive fitness is not included in the total merit index, such as in Italian Brown Swiss. Since 2002, the Italian Brown Swiss Cattle Breeders Association (Verona, Italy) has been collecting data on BCS once on all registered first-parity cows (Dal Zotto et al., 2005, 2007; Rossoni et al., 2007a,b). Therefore, the aim of this work was to investigate the genetic relationship between BCS and fertility traits in the Italian Brown Swiss population, testing the possible nonlinearity of this relationship.

\section{MATERIALS AND METHODS}

\section{Data Collection and Editing Procedure}

Body condition measures and pedigree information were provided by the Italian Brown Swiss Cattle Breeders Association (Verona, Italy), and insemination and production records were obtained from the Breeders Association of Bolzano-Bozen Province (Italy), as previously detailed by Tiezzi et al. (2011, 2012). Data included 16,324 first-parity and 10,086 second-parity cows reared in 1,413 herds. Animals calved from 2002 to 
2007 and were progeny of 420 AI bulls. Body condition score was routinely measured once on first-lactation cows by trained classifiers according to the method of Edmonson et al. (1989), based on a 5-point scale with 0.25 -unit increments and evaluating 8 body areas. For this study, records of BCS from primiparous cows collected between 10 and 180 DIM were considered, according to the official evaluation.

Production traits were peak milk yield (pMY; kg), lactation milk yield (IMY; $\mathrm{kg}$ ), and lactation length $(\mathbf{L L} ; \mathrm{d})$, and fertility traits were interval from parturition to first service (iPF), interval from first service to conception (iFC), interval from parturition to conception (iPC), number of inseminations to conception (INS), conception at first service (CFS), and nonreturn rate at $56 \mathrm{~d}$ after first service (NR56). Records were submitted to statistical analysis if iPF and iPC comprised between 21 and $400 \mathrm{~d}$, and between 0 and $400 \mathrm{~d}$ for iFC. The intervals were adopted to simulate their use for genetic evaluation of animals, but only few cows showed values $\geq 400 \mathrm{~d}$ (Tiezzi et al., 2011). Also, $\mathrm{iFC}$ and $\mathrm{iPC}$ were considered censored if a subsequent calving was not recorded. Interval fertility measures, production traits, and BCS were treated as linear Gaussian variables.

The INS was coded as an ordinal categorical variable according to the number of services needed to achieve pregnancy, and inseminations occurring within $6 \mathrm{~d}$ were considered as a single service. The variable consisted of 5 classes. An arbitrary penalty of 1 insemination was added to records that missed subsequent calving, following an approach similar to that of Hou et al. (2009) for days open. Conception at first service and NR56 were coded as dichotomous variables according to the achievement of pregnancy at first service for CFS, or the occurrence of a second breeding within $56 \mathrm{~d}$ after first service (0) or not (1) for NR56.

In addition to considering BCS as a linear measure on the 5-point scale and with the aim of testing the nonlinearity between body condition and fertility, cows were also classified as thin or fat, based on their adjusted BCS. Body condition scores were preadjusted for DIM, through a fourth-order Ali-Schaeffer regression, and year-season of scoring, through a generalized linear model; the residuals were standardized to mean 0 and residual standard deviation 1 , and records were categorized as fat cow $=1$ if they exceeded the value of $1(0$ otherwise), and as thin cow $=1$ if they were below the value of -1 ( 0 otherwise) residual standard deviation.

Herds with less than 3 cows were discarded from the data set as well as cows that moved to a different herd during the period of the study. Sires were required to have a minimum of 5 daughters with records in first lactation, distributed across at least 3 herds. Finally, records from classifiers who scored less than 20 cows were removed.

\section{Statistical Analysis}

All the computations in the present work were performed using threshold model (TM) software (Legarra et al., 2008). Univariate threshold and censored linear analyses were used to estimate variance components for Gaussian and dichotomous categorical variables, respectively, according to the following models:

$$
\mathbf{y}=\mathbf{X} \boldsymbol{\beta}+\mathbf{Z}_{\mathbf{h}} \mathbf{h}+\mathbf{Z}_{\mathrm{cl}} \mathbf{c l}+\mathbf{Z}_{\mathrm{s}} \mathbf{s}+\mathbf{e}
$$

and

$$
\lambda=\mathbf{X} \boldsymbol{\beta}+\mathbf{Z}_{\mathbf{h}} \mathbf{h}+\mathbf{Z}_{\mathrm{cl}} \mathbf{c l}+\mathbf{Z}_{\mathrm{s}} \mathbf{s}+\mathbf{Z}_{\mathrm{ss}} \mathbf{s} \mathbf{s}+\mathbf{Z}_{\mathrm{t}} \mathbf{t}+\mathbf{e},
$$

where $\mathbf{y}$ is the vector of observations for linear traits (BCS, iPF, iFC, iPC, pMY, lMY, and LL); $\lambda$ is the vector of unobserved liabilities for the dichotomous categorical traits (fat cow, thin cow, CFS, and NR56); $\boldsymbol{\beta}$ is the vector of systematic effects (specific to each class of traits); $\mathbf{h}$ is the vector of random effects for herds; $\mathbf{c l}$ is the vector of random effects for classifiers (only for BCS, fat cow, and thin cow); $\mathbf{s}$ is the vector of random genetic effects for sires of cows; ss is the vector of random effects for service sires (only for CFS and NR56); $\mathbf{t}$ is the vector of random effects for technicians (only for CFS and NR56); e is the vector of random residuals; and $\mathbf{X}, \mathbf{Z}_{\mathrm{h}}, \mathbf{Z}_{\mathrm{cl}}, \mathbf{Z}_{\mathrm{s}}, \mathbf{Z}_{\mathrm{ss}}$, and $\mathbf{Z}_{\mathrm{t}}$ are incidence matrices relating the corresponding effects to the dependent variable. The ordinal categorical variable (INS) was analyzed under a censored threshold model, including the same effects of Gaussian traits, except for classifier factor. Fixed effects were year-month and DIM at scoring modeled as fourth-order Ali-Schaeffer regression for BCS; year-month of first calving for pMY, lMY, and LL; year-month of calving of the respective parity for $\mathrm{iPF}$ and $\mathrm{iPC}$; and the respective year-month of first insemination for iFC, INS, CFS, and NR56. No fixed effects were considered for fat cow and thin cow, as these traits were preadjusted for year-month and DIM at scoring. The Ali-Schaeffer regression gave the best fitting to the overall BCS curve according to a preliminary analysis through the generalized linear model (SAS Institute Inc., Cary, NC). Linear Gaussian models for handling right-censored records were developed by Korsgaard et al. (1998) and Sorensen et al. (1998) using the technique of data augmentation under a Bayesian framework (Tanner and Wong, 1987). 
Bivariate analyses were carried out to investigate the genetic relationships of body condition traits with fertility and production traits of first-parity cows, and fertility of second parity-cows. Covariance components were obtained under linear-linear, threshold-linear, and threshold-threshold sire models. Systematic and random effects were identical to the univariate analyses. Gibbs sampling was implemented in a Bayesian framework. Bounded uniform priors were used for all systematic effects, and null means and normal univariate or bivariate prior distributions for sire (s), herd (h), classifier (cl), service sire (ss), and technician (t) random effects were assumed. In matrix notation, these were as follows:

$$
\begin{gathered}
{\left[\begin{array}{l}
\mathbf{s}_{\mathbf{1}} \\
\mathbf{s}_{\mathbf{2}}
\end{array}\right] \sim N(0, \mathbf{G} \otimes \mathbf{A}),} \\
{\left[\begin{array}{l}
\mathbf{c l}_{\mathbf{1}} \\
\mathbf{c} \mathbf{l}_{\mathbf{2}}
\end{array}\right] \sim N(0, \mathbf{C L} \otimes \mathbf{I}),} \\
{\left[\begin{array}{l}
\mathbf{h}_{\mathbf{1}} \\
\mathbf{h}_{\mathbf{2}}
\end{array}\right] \sim N(0, \mathbf{H} \otimes \mathbf{I}),} \\
{\left[\begin{array}{l}
\mathbf{s s}_{\mathbf{1}} \\
\mathbf{s s}_{\mathbf{2}}
\end{array}\right] \sim N(0, \mathbf{S S} \otimes \mathbf{I}),}
\end{gathered}
$$

and

$$
\left[\begin{array}{l}
\mathbf{t}_{\mathbf{1}} \\
\mathbf{t}_{\mathbf{2}}
\end{array}\right] \sim N(0, \mathbf{T} \otimes \mathbf{I})
$$

where $\mathbf{G}\left[\begin{array}{cc}\sigma_{s 1}^{2} & \sigma_{s 12} \\ \sigma_{s 21} & \sigma_{s 2}^{2}\end{array}\right]$ is the $2 \times 2$ sire covariance matrix, A is the numerator relationship matrix between sires, $\mathbf{H}\left[\begin{array}{cc}\sigma_{h 1}^{2} & \sigma_{h 12} \\ \sigma_{h 21} & \sigma_{h 2}^{2}\end{array}\right]$ is the herd covariance matrix, and $\mathbf{I}$ is an identity matrix; $\sigma_{s 1}^{2}$ and $\sigma_{s 2}^{2}$ are the sire variances for traits 1 and 2, respectively; $\sigma_{h 1}^{2}$ and $\sigma_{h 2}^{2}$ are the herd variances for traits 1 and 2, respectively; $\sigma_{s 12}\left(\right.$ or $\left.\sigma_{s 21}\right)$ is the sire covariance between traits 1 and 2 ; and $\sigma_{h 12}$ (or $\sigma_{h 21}$ ) is the herd covariance between traits 1 and 2 . As the classifier, service sire, and technician effects were parity specific (e.g., classifier effect was considered only for BCS), these factors were fitted on a single trait in bivariate analyses. Thus, we had $\mathbf{C L}\left[\begin{array}{cc}\sigma_{c l 1}^{2} & 0 \\ 0 & 0\end{array}\right]$ for the classifier covariance matrix, $\mathbf{S S}\left[\begin{array}{cc}\sigma_{s s 1}^{2} & 0 \\ 0 & 0\end{array}\right]$ for the service sire covariance matrix, and $\mathbf{T}\left[\begin{array}{cc}\sigma_{t 1}^{2} & 0 \\ 0 & 0\end{array}\right]$ for the technician covariance matrix, where $\sigma_{c l 1}^{2}, \sigma_{s s 1}^{2}$, and $\sigma_{t 1}^{2}$ are the classifier, service sire, and technician variances for trait 1 , respectively.

Residuals were assumed correlated and normally distributed:

$$
\left[\begin{array}{l}
\mathbf{e}_{1} \\
\mathbf{e}_{2}
\end{array}\right] \sim N(0, \mathbf{R} \otimes \mathbf{I})
$$

where $\mathbf{R}\left[\begin{array}{cc}\sigma_{e 1}^{2} & \sigma_{e 12} \\ \sigma_{e 21} & \sigma_{e 2}^{2}\end{array}\right]$ is the residual covariance matrix for the linear-linear and threshold-threshold analyses for INS; $\sigma_{e 1}^{2}$ and $\sigma_{e 2}^{2}$ are the residual variances for traits 1 and 2 , respectively, and $\sigma_{e 12}\left(\right.$ or $\left.\sigma_{e 21}\right)$ is the covariance between the traits. For threshold analyses on dichotomous traits (fat cow, thin cow, CFS, and NR56) the residual variance was fixed to 1 . Thus, the residual covariance matrix became $\mathbf{R}=\left[\begin{array}{cc}1 & \sigma_{e 12} \\ \sigma_{e 21} & \sigma_{e 2}^{2}\end{array}\right]$ for the threshold-linear analyses, and $\mathbf{R}=\left[\begin{array}{ll}1 & 0 \\ 0 & 1\end{array}\right]$ for the thresholdthreshold analyses with 2 dichotomous traits, because in this case, the residual covariance was fixed to zero, similar to the approach of Heringstad et al. (2004) on clinical mastitis.

For univariate models, a single Gibbs chain of 250,000 samples was obtained, whereas for bivariate models, 550,000 iterations were run. In all cases, the first 50,000 samples were discarded as burn-in. Samples were stored every 20 iterations for univariate models and 50 iterations for bivariate models, to leave 10,000 samples for inferences. The posterior mean was used as a point estimate of the (co)variance component and the related parameter.

Heritability $\left(\mathrm{h}^{2}\right)$ was computed as

$$
\mathrm{h}^{2}=\frac{4 \sigma_{s}^{2}}{\sigma_{s}^{2}+\sigma_{e}^{2}}
$$

Sire, herd, classifier, technician, service sire, and residual effects were expressed as the ratio of the specific effect to total phenotypic variance. Finally, genetic correlations $\left(\mathrm{r}_{g}\right)$ were calculated as 


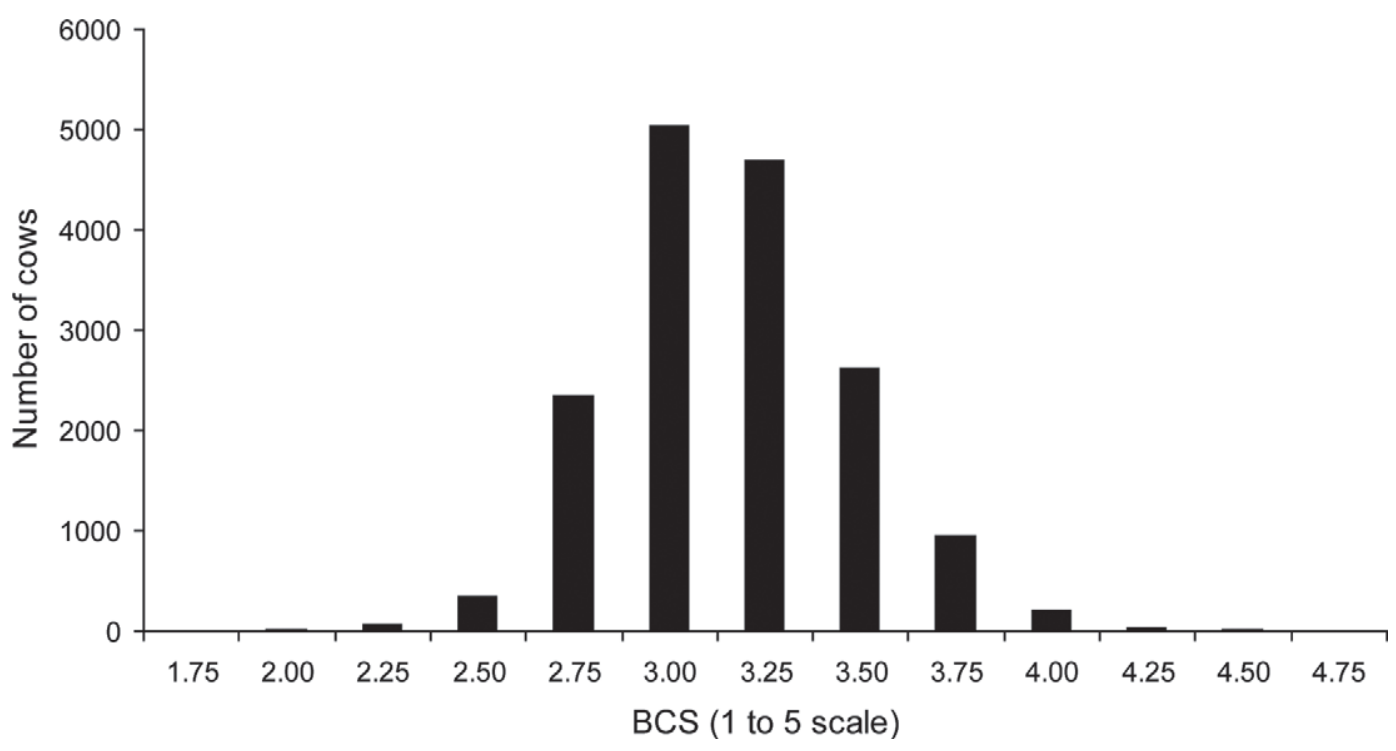

Figure 1. Distribution of BCS.

$$
\mathrm{r}_{g}=\frac{\operatorname{cov}_{s}(x, y)}{\sigma_{s, x} \sigma_{s, y}}
$$

where $\operatorname{cov}_{s}(x, y)$ is the sire additive genetic covariance between traits $x$ and $y$, and $\sigma_{s, x}$ and $\sigma_{s, y}$ are the respective additive genetic standard deviations.

\section{RESULTS AND DISCUSSION}

\section{Descriptive Statistics}

The mean for BCS was 3.16 (Table 1); the values ranged between 1.75 and 4.75. Body condition score approximated a Gaussian distribution (Figure 1), with 3.00 being the most frequent score, and values lower than 2.50 and higher than 4.00 being rare. These results are in accordance with statistics of Dal Zotto et al. (2007), who reported a mean value (SD) of 3.20 (0.35) in the Italian Brown Swiss population. Body condition score for thin cow and fat cow averaged 2.72 and 3.64, respectively. Means and standard deviations for production traits in first lactation (Table 1) and reproductive performance in first and second lactation (Table 2) are close to values of Tiezzi et al. (2011, 2012) and, for milk yield, to those of Cipolat-Gotet et al. (2012), Cecchinato et al. (2013), and Bittante et al. (2012), who summarized the results of 9 studies that compared Brown Swiss with Holstein cows.

\section{Heritability of Body Condition, Production, and Fertility Traits}

Heritability for BCS was 0.141 (lower and upper bound of the $95 \%$ highest posterior density region: 0.096 to 0.188 ; Table 3 ), which is comparable to estimates of 0.15 and 0.19 reported by Dal Zotto et al. (2007) and Rossoni et al. (2007a), respectively, in Italian Brown Swiss cows, but lower than heritabilities from other studies that scored BCS once per cow during lactation. Zink et al. (2011) estimated a heritability of 0.30 for

Table 1. Descriptive statistics of body condition and production traits of first-parity cows $(\mathrm{n}=16,324)$

\begin{tabular}{lcccc}
\hline Trait $^{1}$ & Mean & SD & Minimum & Maximum \\
\hline Body condition & & & & \\
BCS & 3.16 & 0.32 & 1.75 & 4.75 \\
BCS for fat cow & 3.64 & 0.19 & 3.25 & 3.75 \\
BCS for thin cow & 2.72 & 0.15 & 1.75 & 3.25 \\
First-parity production & 25.7 & & & 50 \\
pMY (kg) & 6,972 & 1,902 & 7.51 & 14,455 \\
lMY (kg) & 338 & 73.9 & 45 & 639 \\
LL (d) &
\end{tabular}

${ }^{1}$ Fat cow $=$ cow classified as fat, based on its adjusted BCS; thin cow $=$ cow classified as thin, based on its adjusted BCS; pMY = peak milk yield; lMY = lactation milk yield; LL = lactation length. 
Table 2. Descriptive statistics of fertility traits for first- and second-parity cows, and percentage of censored records

\begin{tabular}{lccccccc}
\hline & \multicolumn{2}{c}{ First-parity cows $(\mathrm{n}=16,324)$} & & \multicolumn{2}{c}{ Second-parity cows $(\mathrm{n}=10,086)$} \\
\cline { 2 - 3 } \cline { 7 - 8 } Trait $^{1}$ & Mean & SD & Censored $(\%)$ & & Mean & SD & Censored (\%) \\
\hline iPF (d) & 90.7 & 41.9 & 0.00 & & 90.8 & 41.5 & 0.00 \\
iFC (d) & 38.8 & 60.9 & 13.2 & & 36.9 & 58.4 & 17.6 \\
iPC (d) & 129.5 & 71.6 & 13.2 & & 127.6 & 68.7 & 17.6 \\
INS (no.) & 1.76 & 1.05 & 14.3 & & 1.74 & 1.04 & 18.4 \\
CFS & 0.55 & 0.50 & 0.00 & & 0.56 & 0.50 & 0.00 \\
NR56 & 0.71 & 0.46 & 0.00 & & 0.71 & 0.46 & 0.00 \\
\hline
\end{tabular}

$\overline{{ }_{1} \mathrm{PF}}=$ interval from parturition to first service; $\mathrm{iFC}=$ interval from first service to conception; $\mathrm{iPC}=$ interval from parturition to conception; INS = number of inseminations to conception; CFS $=$ conception at first service; NR56 = nonreturn rate at $56 \mathrm{~d}$ after first service.

BCS measured on a 9-point scale in Czech Holsteins, Dechow et al. (2004) a heritability of 0.22 in US Holsteins, and Pryce et al. (2002) a heritability of 0.39 in UK Holsteins. Bastin et al. (2010a,b), using random regression models on repeated scores of BCS in Canadian Ayrshire and Holstein cows, reported increasing estimates of heritability during lactation, with values not much different from heritability of the present work during the first $6 \mathrm{mo}$ of lactation. Buttchereit et al. (2011) reported an opposite trend from that of Bastin et al. (2010a,b) and much higher heritabilities in German
Holsteins, but all cows were from only 1 experimental farm. Heritabilities for fat cow and thin cow were 0.122 (lower and upper bound of the 95\% highest posterior density region: 0.065 to 0.182 ) and 0.115 (lower and upper bound of the $95 \%$ highest posterior density region: 0.063 to 0.169 ), respectively (Table 3 ). The estimates for these 2 categorized traits are similar to heritability for BCS treated as linear score (Figure 2).

Herd explained only a minor part of the variation for BCS (7.4\%), fat cow (4.6\%), and thin cow $(7.0 \%)$, whereas the quota of variation explained by classifier

Table 3. Estimates ${ }^{1}$ of heritability and random effects for body condition, production, and fertility traits

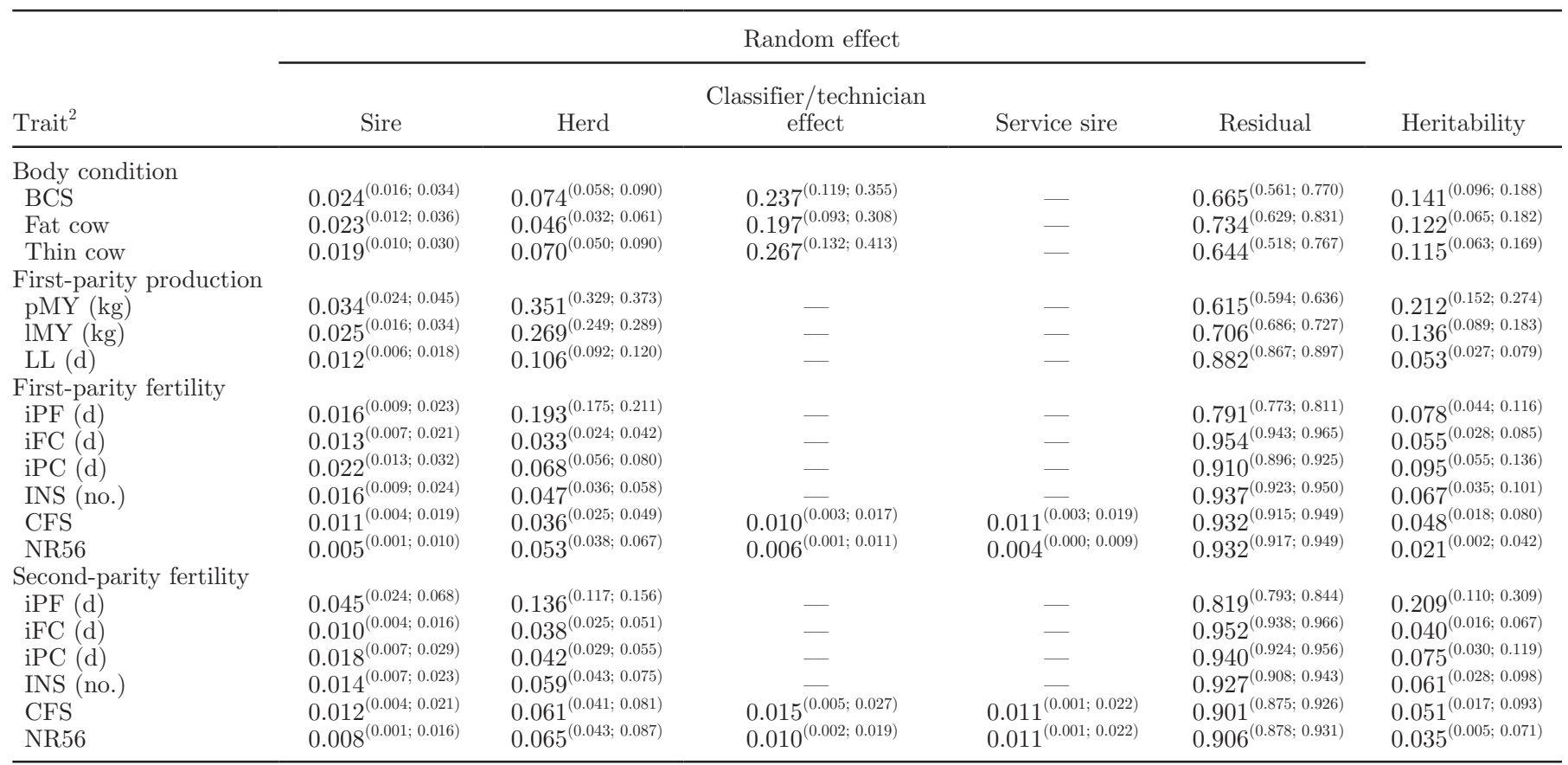

${ }^{1}$ Estimates are the means of the marginal posterior densities for the random effects and heritability. Bounds of the $95 \%$ high posterior density interval are within parentheses.

${ }^{2}$ Fat cow $=$ cow classified as fat, based on its adjusted BCS; thin cow $=$ cow classified as thin, based on its adjusted BCS; pMY $=$ peak milk yield; $\mathrm{lMY}=$ lactation milk yield; $\mathrm{LL}=$ lactation length; $\mathrm{iPF}=$ interval from parturition to first service; iFC $=$ interval from first service to conception; $\mathrm{iPC}=$ interval from parturition to conception; INS $=$ number of inseminations to conception; CFS $=$ conception at first service; NR56 = nonreturn rate at $56 \mathrm{~d}$ after first service. 


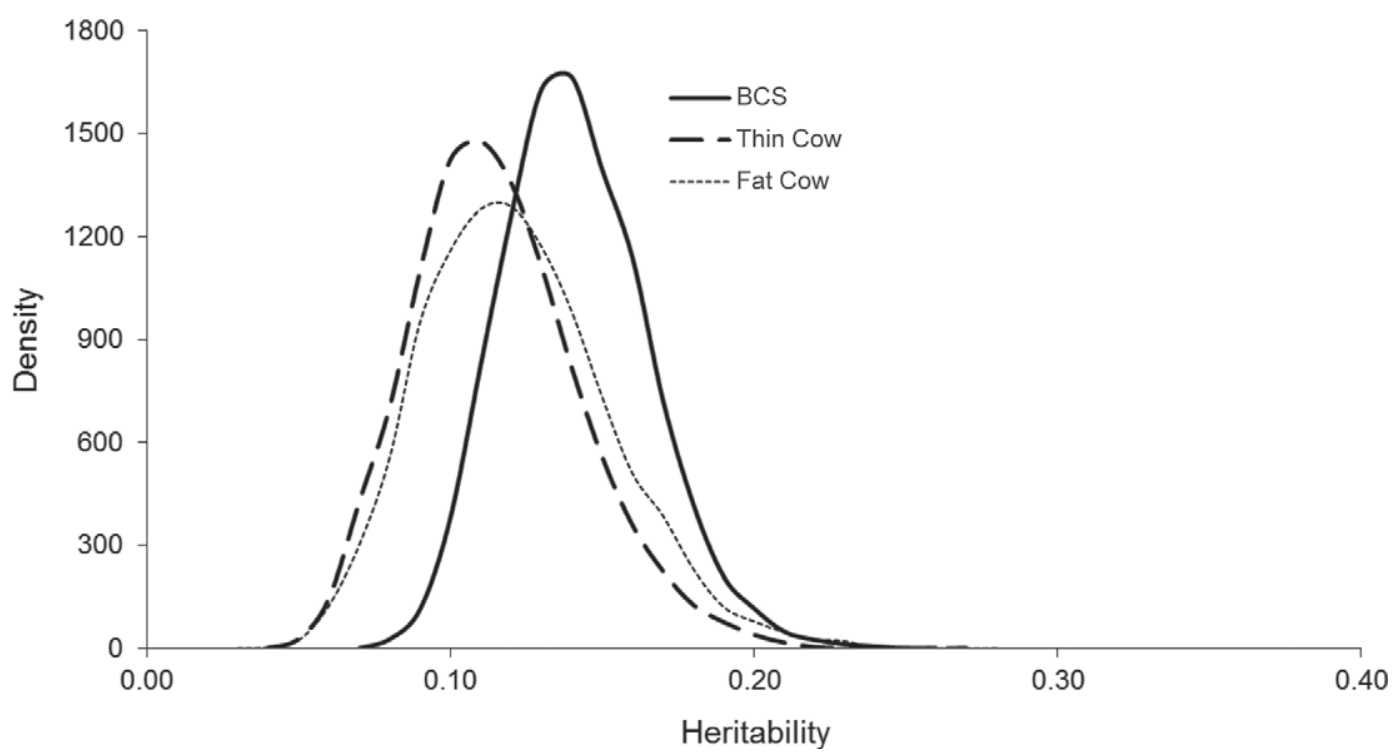

Figure 2. Marginal posterior distributions of the heritability for BCS, cow classified as thin, and cow classified as fat, based on their adjusted BCS.

effect was $23.7,19.7$, and $26.7 \%$, respectively (Table 3 ). In the present study, quantifying the variation due to the random effect of classifier is not a robust measure of repeatability and consistency in scoring, as cows were scored only once by a single technician. In any case, given the large variation among classifiers in scoring, it is recommended to account for this effect when estimating genetic parameters for body condition traits.

Heritabilities for pMY, IMY, and LL were 0.212, 0.136 , and 0.053 , respectively (Table 3 ), which are different from previous reports on the same breed (Samoré et al., 2007; Cecchinato et al., 2011). Herd explained an appreciable quota of the variation in $\mathrm{pMY}$ and IMY, and a smaller part in LL.

Finally, heritabilities for fertility traits ranged from 0.021 (NR56) to 0.095 (iPC) in first lactation, and from 0.035 (NR56) to 0.209 (iPF) in second lactation (Table 3). These estimates are in accordance to values reported by Tiezzi et al. (2012) and similar to the value of 0.05 for calving interval assessed by Dal Zotto et al. (2007) on a larger Brown Swiss population. Herd was of certain importance in explaining the variation of reproductive performance only for iPF.

\section{Phenotypic Relationships of Body Condition with Production and Fertility Traits}

Phenotypic correlations of BCS, fat cow, and thin cow with production and reproductive performance were very low and comprised between -0.099 (thin cow with pMY) and 0.129 (thin cow with iPF of first-parity cows; Table 4). It is worth noting that the correlations between BCS and production traits were favorable, with $100 \%$ posterior probability of being positive between $\mathrm{BCS}$ and $\mathrm{pMY}$, and BCS and $\mathrm{IMY}$, and $100 \%$ posterior probability of being negative between BCS and LL. Dechow et al. (2001) estimated low phenotypic correlations between BCS and production in US Holsteins, but positive at calving and negative thereafter, thus indirectly demonstrating that it is the change in BCS that is correlated with milk yield. Similar results were reported by Loker et al. (2012) on Canadian Holsteins. Very low and unfavorable relationships between production and BCS loss during lactation were obtained by Dechow et al. (2002). In a Swiss study, De Haas et al. (2007a) assessed a moderate and unfavorable $(-0.35)$ phenotypic correlation between production and BCS in Holstein cows.

Body condition score was favorably correlated with fertility of first-parity cows, particularly with iPF and iPC (Table 4), in accordance with Domecq et al. (1997), Suriyasathaporn et al. (1998), Gillund et al. (2001), and Dechow et al. (2004), who reported very low phenotypic relationships between BCS and reproductive fitness. The carryover effect of BCS evaluated in first lactation to fertility recorded in second lactation was negligible, with estimates lower than $6 \%$ for all traits (Table 4).

Comparing the phenotypic correlations of BCS, fat cow, and thin cow with production and fertility traits makes clear the nonlinearity of the relationships. Differently from BCS, fat cow was not related to contemporary pMY and IMY, and only LL showed a small and negative correlation with fat cow (Table 4). However, 
Table 4. Estimates ${ }^{1}$ of genetic and phenotypic correlations of body condition traits with production of first-parity cows, and fertility of firstand second-parity cows

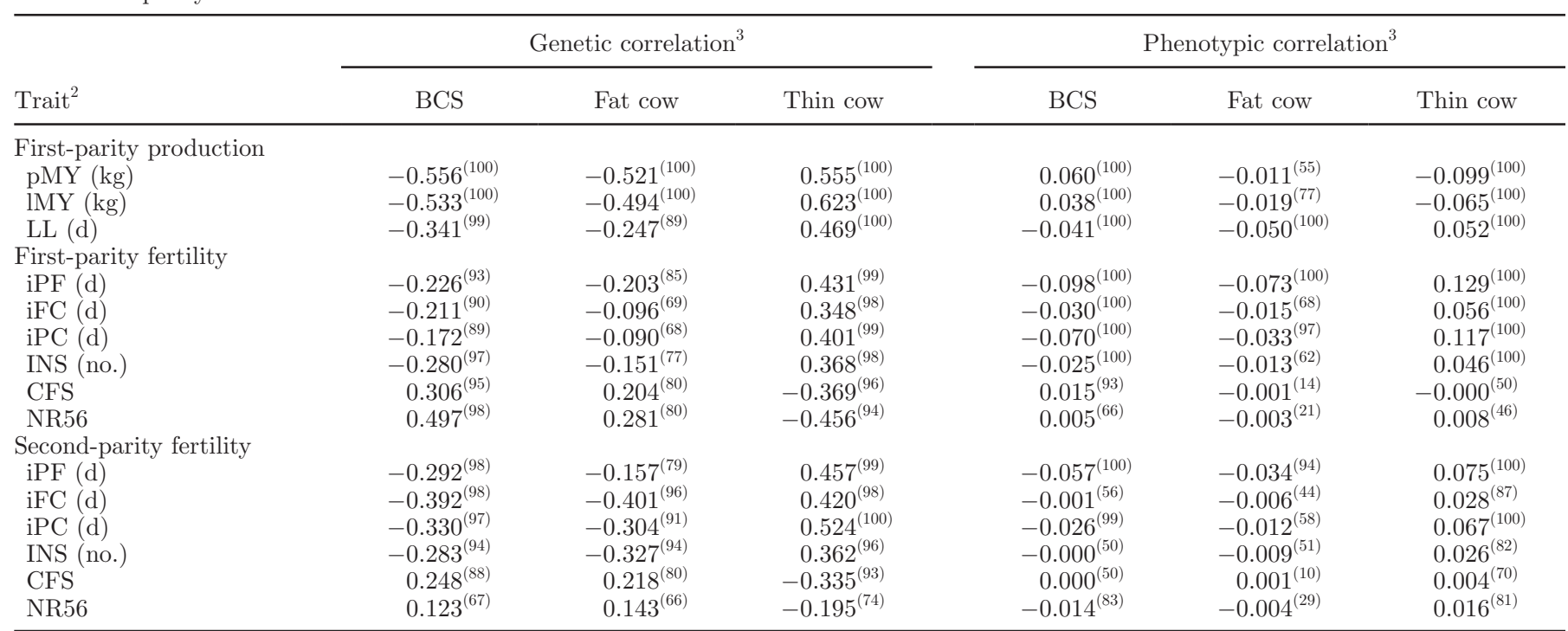

${ }^{1}$ Estimates are the means of the marginal posterior densities for the correlation. The posterior probability (\%) for positive correlations greater than zero or for negative correlations lower than zero is given within parentheses.

${ }^{2} \mathrm{pMY}=$ peak milk yield; $\mathrm{lMY}=$ lactation milk yield; $\mathrm{LL}=$ lactation length; $\mathrm{iPF}=$ interval from parturition to first service; $\mathrm{iFC}=\mathrm{interval}$ from first service to conception; $\mathrm{iPC}=$ interval from parturition to conception; INS $=$ number of inseminations to conception; $\mathrm{CFS}=$ conception at first service; NR56 = nonreturn rate at $56 \mathrm{~d}$ after first service.

${ }^{3}$ Fat cow $=$ cow classified as fat, based on its adjusted BCS; thin cow $=$ cow classified as thin, based on its adjusted BCS.

LL can be considered more as a fertility than production trait, being high especially in repeat breeders and open cows. The difference with respect to BCS is even clearer in the case of reproductive performance, as the phenotypic correlations between fat cow and fertility traits recorded in first and second parity were almost null, with the only exception of the small but significant relationship between fat cow and iPF in first lactation. Differently from fat cow, the correlations of thin cow with production and fertility traits were always higher than those obtained for BCS, with the only exception of CFS in first lactation (Table 4). Apart from the obvious difference in sign, and from the entity of estimates, the meaning of the phenotypic correlations observed for thin cow is the same as that for BCS. The results seem to support the existence of a negative phenotypic effect of fatness of cow on its production, even though it should be reiterated here that, in the present study, only 1 measure of BCS per cow was collected during the first 6 mo of lactation, and thus it is difficult to precisely predict the energy balance and mobilization of body reserves of the cow. Although for thin cow this is less relevant, for fat cow this becomes of major importance, as the sudden mobilization of body reserves can lead to scarce reproductive performance of fat cows. Having a single measure per lactation does not allow modeling the evolution of NEB during lactation and, thus, it is not possible to assess the change in body reserves of overconditioned cows.

\section{Genetic Relationships Between Body Condition and Production Traits}

Genetic correlations of body condition traits with pMY, lMY, and LL were moderate to high, and comprised between -0.556 and 0.623 (Table 4), in accordance with estimates reported by Veerkamp et al. (2001), Pryce et al. (2002), and Dal Zotto et al. (2007). Using random regression models on Holstein data, Buttchereit et al. (2011) and Loker et al. (2012) found a strong genetic antagonism between BCS and milk yield in mid lactation, and small correlations at the beginning and at the end of lactation. De Haas et al. (2007a), comparing the data of Holstein, Brown Swiss, and Red and White breeds in Switzerland, found similar antagonistic genetic relationships between BCS and milk yield $(-0.45$ in Holsteins) or muscularity $(-0.35$ in Brown Swiss and -0.55 in Red and White cows). The comparison of phenotypic and genetic correlations suggests that the low phenotypic relationships between fat cow and production traits could be the result of opposite effects of genetics and environment.

\section{Genetic Relationships Between BCS and Contemporary Fertility Traits}

Genetic correlations between BCS and contemporary fertility ranged from -0.280 (BCS with INS) to 0.497 (BCS with NR56; Table 4). The scientific literature 
has reported similar or larger estimates between linear measures of BCS and reproductive performance. The genetic correlation between BCS and calving interval in Brown Swiss cattle was -0.35 in the study of Dal Zotto et al. (2007) and -0.67 in Rossoni et al. (2007a), and it was -0.48 in Holstein cows (Pryce et al., 2002). Dechow et al. (2004) estimated a correlation of -0.30 between BCS and days open, and Zink et al. (2011) reported values of $-0.30,-0.46$, and -0.45 between $\mathrm{BCS}$ and $\mathrm{iFC}, \mathrm{iPC}$, and $\mathrm{PPF}$, respectively.

Cows classified as fat showed weaker relationships with contemporary fertility compared with BCS, but of the same sign, and thus genetically fat cows are expected to be genetically slightly more fertile (Table 4). Again, this means that the negative effect of overconditioning on cow fertility should be merely environmental, as it could be the rapid fat mobilization that causes metabolic and reproductive disorders. Contrarily, thin cow was the body condition trait more related to contemporary fertility, as depicted in Figure 3, and genetic correlations ranged between -0.456 (thin cow with NR56) and 0.431 (thin cow with iPF).

The relationship between BCS measured once in first lactation and fertility is not strong if we consider a linear relationship between the 2 traits, but the meaning changes if we assume the 2 traits to be nonlinearly related. In fact, even if the biological meaning of genetic correlations is the same (better condition = higher fertility), fat cow showed a weaker relationship with reproductive traits compared with the relationship between BCS and reproductive traits, suggesting that higher conditioning (in the range we measured it) did not affect very much fertility. On the other hand, the relationship between thin cow and fertility was notably higher than that between BCS and fertility, meaning that genetically much more-conditioned cows in first lactation did not hamper fertility, whereas genetically less-conditioned cows hampered severely their fertility in first lactation. Thus, considering BCS as a linear measure assessed once per lactation may be not the best predictor of contemporary fertility, but affording a different treatment of the measure, exacerbating the measures of poor conditioning, can lead to better results in predicting cow contemporary reproductive fitness.

\section{Genetic Relationships Between BCS and Subsequent Fertility Traits}

Surprisingly, BCS recorded in first lactation was more favorably related to interval fertility traits recorded in second lactation $(-0.392$ to -0.292$)$ than during contemporary lactation $(-0.226$ to -0.172 ; Table 4$)$. Regarding success traits, BCS was more favorably related to CFS and NR56 measured on contemporary (0.306 and 0.497 , respectively) than subsequent (0.123 to 0.248 , respectively) lactation cows. The favorable genetic relationship between BCS of first-parity cows and INS of second-parity cows $(-0.283)$ was very simi-

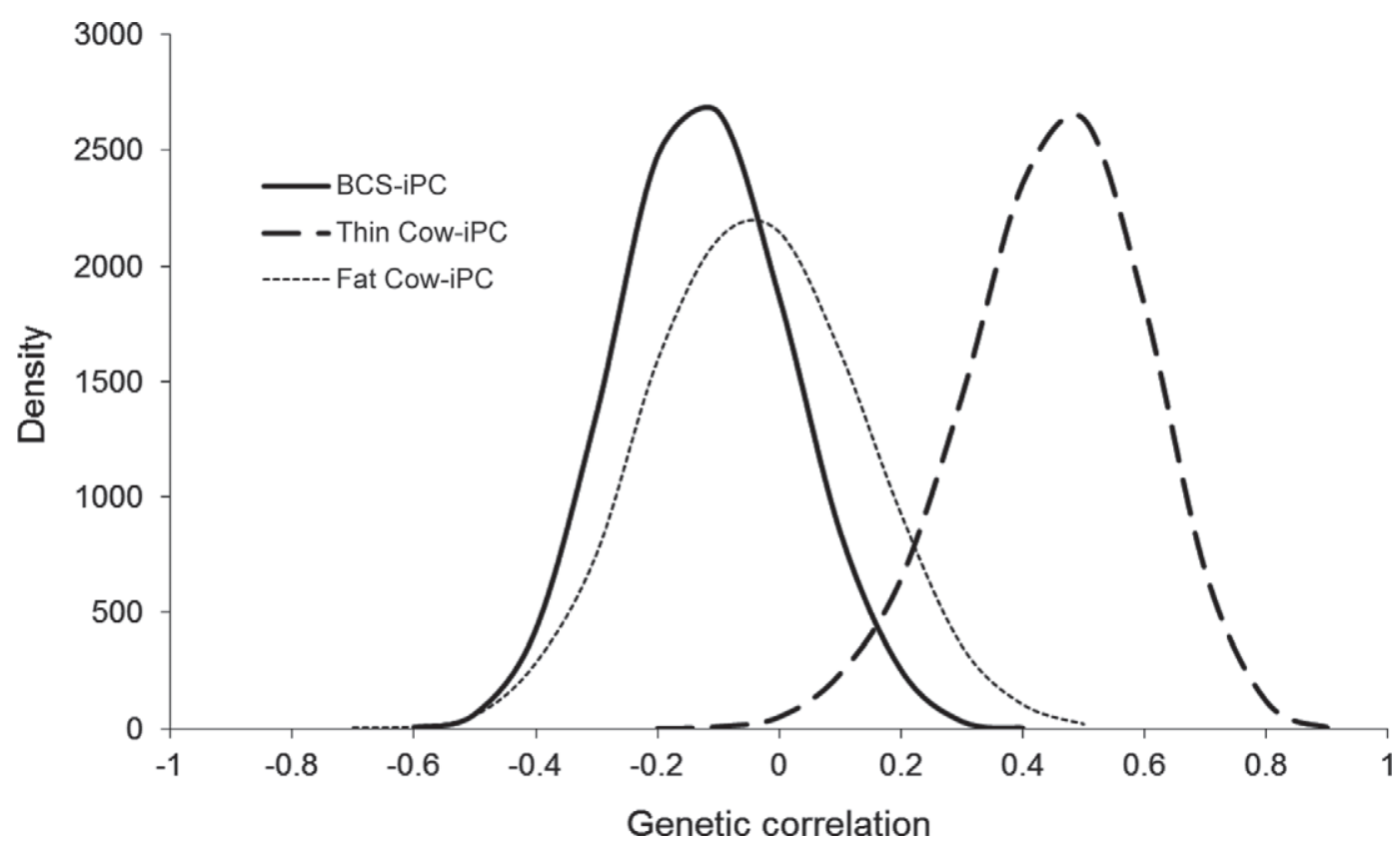

Figure 3. Marginal posterior distributions of the genetic correlation of interval from parturition to conception (iPC; d) for first-lactation cows BCS, cow classified as thin, and cow classified as fat, based on their adjusted BCS. 
lar to the estimate obtained between BCS and INS in first lactation $(-0.280)$, and intermediate compared with those calculated for interval and success traits. In summary, BCS of first-parity cows exhibited favorable genetic relationships with fertility traits measured on both first and second lactation, but the effect was more clear on success traits during contemporary lactation and on interval traits measured after second calving and, thus, changes in body condition of primiparous cows have carryover effects on second-parity cows, especially on the establishment of sexual cycles or on the regularity/visibility of estrus, or both.

The pattern found in first lactation about exacerbating the nonlinearity of the relationship between body condition and fertility can be found also in second lactation; in this case, fat cow showed genetic correlations from -0.401 to 0.218 with fertility, which are similar to relationships between BCS and fertility $(-0.392$ to 0.248 ), but thin cow resulted in stronger genetic correlations, ranging from -0.335 to 0.524 . Zink et al. (2011) reported similar relationships of BCS in first lactation and $\mathrm{iPC}$ and $\mathrm{PPF}$ in second lactation, and lower correlation between BCS and iFC. However, our study showed how body condition could depress reproductive efficiency, especially if the cow is poorly conditioned.

\section{CONCLUSIONS}

The favorable genetic correlations between BCS and fertility often found in the literature and in the present study are not a demonstration of the linearity of the relationship, but of the fact that, genetically, the problems of energy deficit dominates on those of overconditioning. When the body condition was not considered to be linearly related to fertility across its range, stronger relationships with fertility were estimated. Actually, considering that thin cow leads to better prediction of fertility, whereas the probability of having a fat cow does not show a relevant relationship, suggests that the negative effect of overconditioning on fertility is primarily phenotypic. Fertility of secondlactation cows was still related to body condition in first lactation, and a similar pattern of nonlinearity between condition and fertility was detected. In summary, the results showed that a nonlinear relationship exists between body condition and fertility, although it was not possible to quantify it. Considering body condition as nonlinearly related to fertility can lead to good prediction of fertility, even if a single measure of BCS per cow is available. Thin cows, more than BCS, can be a correlated trait when the selection for reproductive efficiency is not conducted through direct fertility measurements.

\section{ACKNOWLEDGMENTS}

The authors thank Trento Province (Italy) for financial support, the Italian Brown Swiss Cattle Breeders Association (ANARB, Verona, Italy) for supplying body condition records and pedigree information, the Breeders Association of Bolzano-Bozen Province (Italy) for providing fertility field data, and the Superbrown Consortium of Bolzano and Trento (Italy) for technical support.

\section{REFERENCES}

Banos, G., and M. P. Coffey. 2010. Genetic association between body energy measured throughout lactation and fertility in dairy cattle. Animal 4:189-199.

Bastin, C., and N. Gengler. 2013. Genetics of body condition score as an indicator of dairy cattle fertility. A review. Biotechnol. Agron. Soc. Environ. 17:64-75.

Bastin, C., S. Loker, N. Gengler, A. Sewalem, and F. Miglior. 2010a. Genetic relationships between body condition score and reproduction traits in Canadian Holstein and Ayrshire first-parity cows. J. Dairy Sci. 93:2215-2228.

Bastin, C., S. Loker, N. Gengler, A. Sewalem, and F. Miglior. 2010b. Short communication: Genetic relationship between calving traits and body condition score before and after calving in Canadian Ayrshire second-parity cows. J. Dairy Sci. 93:4398-4403.

Berry, D. P., F. Buckley, P. Dillon, R. D. Evans, M. Rath, and R. F. Veerkamp. 2003. Genetic relationships among body condition score, body weight, milk yield, and fertility in dairy cows. J. Dairy Sci. 86:2193-2204.

Biffani, S., M. Marusi, F. Biscarini, and F. Canavesi. 2005. Developing a genetic evaluation for fertility using angularity and milk yield as correlated traits. Interbull Bull. 33:63-66.

Bittante, G., M. Penasa, and A. Cecchinato. 2012. Invited review: Genetics and modeling of milk coagulation properties. J. Dairy Sci. 95:6843-6870.

Buttchereit, N., E. Stamer, W. Junge, and G. Thaller. 2011. Short communication: Genetic relationships among daily energy balance, feed intake, body condition score, and fat to protein ratio of milk in dairy cows. J. Dairy Sci. 94:1586-1591.

Cecchinato, A., C. Cipolat-Gotet, J. Casellas, M. Penasa, A. Rossoni, and G. Bittante. 2013. Genetic analysis of rennet coagulation time, curd-firming rate, and curd firmness assessed over an extended testing period using mechanical and near-infrared instruments. J. Dairy Sci. 96:50-62.

Cecchinato, A., M. Penasa, M. De Marchi, L. Gallo, G. Bittante, and P. Carnier. 2011. Genetic parameters of coagulation properties, milk yield, quality, and acidity estimated using coagulating and noncoagulating milk information in Brown Swiss and HolsteinFriesian cows. J. Dairy Sci. 94:4205-4213.

Cipolat-Gotet, C., A. Cecchinato, M. De Marchi, M. Penasa, and G. Bittante. 2012. Comparison between mechanical and near-infrared methods for assessing coagulation properties of bovine milk. J. Dairy Sci. 95:6806-6819.

Coffey, M. P., G. Simm, W. G. Hill, and S. Brotherstone. 2003. Genetic evaluations of dairy bulls for daughter energy balance profiles using linear type scores and body condition score analyzed using random regression. J. Dairy Sci. 86:2205-2212.

Dal Zotto, R., P. Carnier, L. Gallo, G. Bittante, and M. Cassandro. 2005. Genetic relationship between body condition score, fertility, type and production traits in Brown Swiss dairy cows. Ital. J. Anim. Sci. 4(Suppl. 3):30-32.

Dal Zotto, R., M. De Marchi, C. Dalvit, M. Cassandro, L. Gallo, P. Carnier, and G. Bittante. 2007. Heritabilities and genetic correlations of body condition score and calving interval with yield, 
somatic cell score, and linear type traits in Brown Swiss cattle. J. Dairy Sci. 90:5737-5743.

De Haas, Y., L. L. G. Janss, and H. N. Kadarmideen. 2007a. Genetic and phenotypic parameters for conformation and yield traits in three Swiss dairy cattle breeds. J. Anim. Breed. Genet. 124:12-19.

De Haas, Y., L. L. G. Janss, and H. N. Kadarmideen. 2007b. Genetic correlations between body condition scores and fertility in dairy cattle using bivariate random regression models. J. Anim. Breed. Genet. 124:277-285.

Dechow, C. D., G. W. Rogers, and J. S. Clay. 2001. Heritabilities and correlations among body condition scores, production traits, and reproductive performance. J. Dairy Sci. 84:266-275.

Dechow, C. D., G. W. Rogers, and J. S. Clay. 2002. Heritability and correlations among body condition score loss, body condition score, production and reproductive performance. J. Dairy Sci. 85:3062-3070

Dechow, C. D., G. W. Rogers, L. Klei, T. J. Lawlor, and P. M. VanRaden. 2004. Body condition scores and dairy form evaluations as indicators of days open in US Holsteins. J. Dairy Sci. 87:35343541

Domecq, J. J., A. L. Skidmore, J. W. Lloyd, and J. B. Kaneene. 1997. Relationship between body condition scores and conception at first artificial insemination in a large dairy herd of high yielding Holstein cows. J. Dairy Sci. 80:113-120.

Earle, D. F. 1976. A guide to scoring dairy cow condition. J. Agric. (Victoria) 74:228-231

Edmonson, A. J., I. J. Lean, L. D. Weaver, T. Farver, and G. Webster 1989. A body condition scoring chart for Holstein dairy cows. J. Dairy Sci. 72:68-78

Ferguson, J. D., D. T. Galligan, and N. Thomsen. 1994. Principal descriptors of body condition score in Holstein cows. J. Dairy Sci. $77: 2695-2703$

Friggens, N. C., C. Disenhaus, and H. V. Petit. 2010. Nutritional sub-fertility in the dairy cow: Towards improved reproductive management through a better biological understanding. Animal 4:1197-1213.

Gallo, L., P. Carnier, M. Cassandro, R. Dal Zotto, and G. Bittante. 2001. Test-day genetic analysis of condition score and heart girth in Holstein Friesian cows. J. Dairy Sci. 84:2321-2326.

Gallo, L., P. Carnier, M. Cassandro, R. Mantovani, L. Bailoni, B Contiero, and G. Bittante. 1996. Change in body condition score of Holstein cows as affected by parity and mature equivalent milk yield. J. Dairy Sci. 79:1009-1015.

Gillund, P., O. Reksen, Y. T. Gröhn, and K. Karlberg. 2001. Body condition related to ketosis and reproductive performance in Norwegian dairy cows. J. Dairy Sci. 84:1390-1396.

Gredler, B., C. Fuerst, and J. Sölkner. 2007. Analysis of new fertility traits for the joint genetic evaluation in Austria and Germany. Interbull Bull. 37:152-155.

Hady, P. J., J. J. Domecq, and J. B. Kaneene. 1994. Frequency and precision of body condition scoring in dairy cattle. J. Dairy Sci. $77: 1543-1547$.

Heringstad, B., Y. M. Chang, D. Gianola, and G. Klemetsdal. 2004. Multivariate threshold model analysis of clinical mastitis in multiparous Norwegian dairy cattle. J. Dairy Sci. 87:3038-3046.

Heuer, C., Y. H. Schukken, and P. Dobbelaar. 1999. Postpartum body condition score and results from the first test day milk as predictors of disease, fertility, yield, and culling in commercial dairy herds. J. Dairy Sci. 82:295-304.

Hill, J., and R. Gilbert. 2008. Reduced quality of bovine embryos cultured in media conditioned by exposure to an inflamed endometrium. Aust. Vet. J. 86:312-316.

Hou, Y., P. Madsen, R. Labouriau, Y. Zhang, M. S. Lund, and G. Su. 2009. Genetic analysis of days from calving to first insemination and days open in Danish Holsteins using different models and censoring scenarios. J. Dairy Sci. 92:1229-1239.

Korsgaard, I. R., D. A. Sorensen, and D. Gianola. 1998. Multivariate analysis of censored normal, ordered categorical and Gaussian traits using Gibbs sampling and data augmentation. Pages 493-496 in Proc. 6th World Congr. Genet. Appl. Livest. Prod., Vol. 25, Armidale, Australia.
Kristensen, E., L. Dueholm, D. Vink, J. E. Andersen, E. B. Jakobsen, S. Illum-Nielsen, F. A. Petersen, and C. Enevoldsen. 2006. Withinand across-person uniformity of body condition scoring in Danish Holstein cattle. J. Dairy Sci. 89:3721-3728.

Legarra, A., L. Varona, and E. López de Maturana. 2008. TM Threshold Model. Accessed Dec. 15, 2012. http://snp.toulouse.inra. fr/ alegarra/manualtm.pdf.

Leroy, J. L. M. R., A. Van Soom, G. Opsomer, I. G. F. Goovaerts, and P. E. J. Bols. 2008. Reduced fertility in high-yielding dairy cows: Are the oocyte and embryo in danger? Part II. Mechanisms linking nutrition and reduced oocyte and embryo quality in high-yielding dairy cows. Reprod. Domest. Anim. 43:623-632.

Loker, S., C. Bastin, F. Miglior, A. Sewalem, L. R. Schaeffer, J. Jamrozik, A. Ali, and V. Osborne. 2012. Genetic and environmental relationships between body condition score and milk production traits in Canadian Holsteins. J. Dairy Sci. 95:410-419.

Lowman, B. G., N. Scott, and S. Somerville. 1973. Condition Scoring of Cattle. Bulletin No. 6. East of Scotland College of Agriculture, Edinburgh, UK.

Miglior, F. 2007. Genetic evaluation of reproductive performance in Canadian dairy cattle. Ital. J. Anim. Sci. 6(Suppl. 1):29-37.

Mitchell, R. G., G. W. Rogers, C. D. Dechow, J. E. Vallimont, J. B Cooper, U. Sander-Nielsen, and J. S. Clay. 2005. Milk urea nitrogen concentration: Heritability and genetic correlations with reproductive performance and disease. J. Dairy Sci. 88:4434-4440.

Mulvaney, P. M. 1977. Dairy Cow Condition Scoring. Paper No. 446 Natl. Inst. Res. Dairying, Shinfield, Reading, UK.

Murray, J. A. 1919. Meat production. J. Agric. Sci. 9:174-181.

Nilforooshan, M. A., J. H. Jakobsen, W. F. Fikse, B. Berglund, and H. Jorjani. 2010. Application of a multiple-trait, multiple-country genetic evaluation model for female fertility traits. J. Dairy Sci. 93:5977-5986.

Pryce, J. E., M. P. Coffey, S. H. Brotherstone, and J. A. Woolliams, 2002. Genetic relationships between calving interval and body condition score conditional on milk yield. J. Dairy Sci. 85:1590-1595.

Pryce, J. E., M. P. Coffey, and G. Simm. 2001. The relationship between body condition score and reproductive performance. J. Dairy Sci. 84:1508-1515.

Remppis, S., H. Steingass, L. Gruber, and H. Schenkel. 2011. Effects of energy intake on performance, mobilization and retention of body tissue, and metabolic parameters in dairy cows with special regard to effects of pre-partum nutrition on lactation-A review. Asianaustralas. J. Anim. Sci. 24:540-572.

Rizos, D., A. Gutiérrez-Adán, S. Pérez-Garnelo, J. de la Fuente, M. P. Boland, and P. Lonergan. 2003. Bovine embryo culture in the presence or absence of serum: Implications for blastocyst development, cryotolerance, and messenger RNA expression. Biol. Reprod. 68:236-243.

Roche, J. R., P. G. Dillon, C. R. Stockdale, L. H. Baumgard, and M. J. VanBaale. 2004. Relationships among international body condition scoring systems. J. Dairy Sci. 87:3076-3079.

Roche, J. R., N. C. Friggens, J. K. Kay, M. W. Fisher, K. J. Stafford, and D. P. Berry. 2009. Invited review: Body condition score and its association with dairy cow productivity, health, and welfare. J. Dairy Sci. 92:5769-5801.

Rossoni, A., C. Nicoletti, O. Bonetti, L. Testa, and E. Santus. 2007b. Genetic evaluation for body condition score in Italian Brown Swiss cattle. Ital. J. Anim. Sci. 6(Suppl. 1):198-200.

Rossoni, A., C. Nicoletti, and E. Santus. 2007a. Genetic evaluation for body condition score in Italian Brown Swiss cattle. Interbull Bull. 37:167-169.

Samoré, A. B., C. Romani, A. Rossoni, E. Frigo, O. Pedron, and A. Bagnato. 2007. Genetic parameters for casein and urea content in the Italian Brown Swiss dairy cattle. Ital. J. Anim. Sci. 6(Suppl. 1):201-203.

Sorensen, D., D. Gianola, and I. Korsgaard. 1998. Bayesian mixedeffects model analysis of a censored normal distribution with animal breeding applications. Acta Agric. Scand. A. Anim. Sci. $48: 222-229$.

Studer, E. 1998. A veterinary perspective of on-farm evaluation of nutrition and reproduction. J. Dairy Sci. 81:872-876. 
Suriyasathaporn, W., M. Nielen, S. J. Dieleman, A. Brand, E. N. Noordhuizen-Stassen, and Y. H. Schukken. 1998. A Cox proportional-hazards model with time-dependent covariates to evaluate the relationship between body-condition score and the risks of first insemination and pregnancy in a high-producing dairy herd. Prev. Vet. Med. 37:159-172.

Tanner, M. A., and W. H. Wong. 1987. The calculation of posterior distributions by data augmentation. J. Am. Stat. Assoc. 82:528 540 .

Tiezzi, F., C. Maltecca, A. Cecchinato, M. Penasa, and G. Bittante. 2012. Genetic parameters for fertility of dairy heifers and cows at different parities and relationships with production traits in first lactation. J. Dairy Sci. 95:7355-7362.

Tiezzi, F., C. Maltecca, M. Penasa, A. Cecchinato, Y. M. Chang, and G. Bittante. 2011. Genetic analysis of fertility in the Italian Brown Swiss population using different models and trait definitions. J. Dairy Sci. 94:6162-6172.

Van Hoeck, V., R. G. Sturmey, P. Bermejo-Alvarez, D. Rizos, A. Gutierrez-Adan, H. J. Leese, P. E. J. Bols, and J. L. M. R. Leroy. 2011. Elevated non-esterified fatty acid concentrations during bovine oocyte maturation compromise early embryo physiology. PLoS ONE 6:e23183.

Veerkamp, R. F., C. L. M. Gerritsen, E. P. C. Koenen, A. Hamoen, and G. De Jong. 2002. Evaluation of classifiers that score linear type traits and body condition score using common sires. J. Dairy Sci. 85:976-983.

Veerkamp, R. F., E. P. C. Koenen, and G. De Jong. 2001. Genetic correlations among body condition score, yield, and fertility in first-parity cows estimated by random regression models. J. Dairy Sci. 84:2327-2335.

Waltner, S. S., J. P. McNamara, and J. K. Hillers. 1993. Relationships of body condition score to production variables in high producing Holstein dairy cattle. J. Dairy Sci. 76:3410-3419.

Wathes, D. C., A. M. Clempson, and G. E. Pollott. 2012. Associations between lipid metabolism and fertility in the dairy cow. Reprod. Fertil. Dev. 25:48-61.

Wildman, E. E., G. M. Jones, P. E. Wagner, R. L. Boman, H. F. Troutt Jr., and T. N. Lesch. 1982. A dairy cow body condition scoring system and its relationship to selected production characteristics. J. Dairy Sci. 65:495-501.

Wrenzycki, C., P. De Sousa, E. W. Overström, R. T. Duby, D. Herrmann, A. J. Watson, H. Niemann, D. O'Callaghan, and M. P. Boland. 2000. Effects of superovulated heifer diet type and quantity on relative mRNA abundances and pyruvate metabolism in recovered embryos. J. Reprod. Fertil. 118:69-78.

Zink, V., M. Štípková, and J. Lassen. 2011. Genetic parameters for female fertility, locomotion, body condition score, and linear type traits in Czech Holstein cattle. J. Dairy Sci. 94:5176-5182. 